\title{
Platão e a Arte: \\ algumas observações sobre as origens da Teoria da Arte no ocidente em perspectiva hermenêutica
}

\author{
Plato and the Art: \\ observations on the origins of Art Theory in Western World from a hermeneutic \\ perspective
}

\section{Luciana da Costa Dias}

Doutora em Filosofia pela Universidade do Estado do Rio de Janeiro (UERJ). Professora Associada na Universidade Federal de Ouro Preto (UFOP) - lucianacdias@yahoo.com.br - orcid.org/0000-0001-5627-5431

\begin{abstract}
Resumo
Este artigo aborda como a relação entre arte e verdade (pode a arte expressar a verdade?) é colocada pela primeira vez no mundo ocidental em Platão, com isso se esboçando o horizonte possível de desenvolvimento e interpretação da questão. Objetiva destacar sua relevância para o início da discussão teórica sobre o que é arte, sua função, conceito e como pode ser entendida. Cabe observar que esta abordagem é construída em perspectiva hermenêutico-fenomenológica, a partir do diálogo, sobretudo, com o pensamento de Martin Heidegger.
\end{abstract}

Palavras-chave: Arte. Platão. Verdade. Hermenêutica. Heidegger.

\begin{abstract}
This article approaches the relation between art and truth (can art express truth?) on how it was first set up in the Western world by Plato, who sketches a possible horizon to the development of the question. Aim to highlight his relevance to the early theoretical discussion regarding what art is, its function, concept and how can it be understood. It should be noted that this approach is built in a hermeneutic-phenomenological perspective starting with the contributions from Martin Heidegger's thinking.
\end{abstract}

Keywords: Art. Plato. Truth. Hermeneutic. Heidegger.

Recebido em: 06/11/2018

Aceito em: 29/10/2019 


\title{
1 INTRODUÇÃO
}

\begin{abstract}
Quando (...) se mergulha no passado, ultrapassando suas próprias vivências e recordações, conduzido por perguntas, mas também por desejos, esperanças e inquietudes, se confronta primeiramente vestígios, que se conservaram até hoje e que, em maior ou menor número chegaram até nós (KOSELLECK, 2006, p. 99).
\end{abstract}

Talvez um dos conceitos de mais difícil definição seja justamente o de arte. Aquilo que hoje geralmente se entende por "arte", nunca teve uma definição (ou sequer um status) de caráter unívoco ao longo da história do pensamento ocidental. Pelo contrário, sempre em meio a controvérsias, foi percorrido um longo caminho até que este conceito polissêmico se consolidasse em sua forma atual que - embora ambíguo - é fruto sobretudo das estéticas da modernidade, que, no geral, se caracterizaram por dois pontos: 1) pela afirmação do Belo como intrínseco à arte (daí as "grandes artes" serem sempre as "Belas artes": música, poesia, teatro, pintura, escultura e arquitetura) e 2) pela afirmação da arte (a "bela obra") como fruto do gênio criador de um artista.

Não pretendo aqui abordar de forma extensiva as diferentes concepções as quais o conceito de arte deteve ao longo de mais de 2000 anos de pensamento ocidental, o que seria impossível dentro do escopo de um único artigo. Ao contrário, pretendo realizar um recorte e tratar de um momento considerado significativo para o nascimento da própria teoria estética ou filosofia da arte: um dos registros mais antigos de que se tem notícia a discutir o que seria arte e qual sua função. Trata-se da obra conhecida como A República, escrita pelo filósofo grego Platão na Atenas do século IV a.C. Não por acaso, é com a discussão do citado autor que a relação entre arte e verdade é posta pela primeira vez em pauta - discussão considerada a gênese da própria "teoria da arte". E ao questionar a relação entre arte e verdade, ainda que pela via negativa (como veremos adiante), Platão acaba por delinear o horizonte posterior de toda questão (HEIDEGGER, 2007).

Importante dizer que apesar da abordagem aqui realizada parecer generalizante para alguns, por pretender rediscutir a própria origem da teoria da arte, este se trata de um estudo de caráter essencialmente teórico e bem recortado, pretendendo ser uma revisão à luz de uma metodologia hermenêutica. Assim, observa-se que o método hermenêutico de pesquisa trabalha com a possibilidade da compreensão dos fenômenos históricos à luz da cultura e do todo social, uma possibilidade de filosofia aplicada às ciências humanas que possibilita ao pesquisador mergulhar no universo de análise, procurando interpretar as teorias e os processos manifestados em um 


\section{Luciana da Costa Dias}

determinado objeto histórico a partir da totalidade do fenômeno histórico: possibilitando amplitude na visão de seus objetos, não como fatos isolados mas inserindo-os, necessariamente, dentro de uma tradição (GADAMER, 2004).

Pensar o nascimento da teoria da arte dentro desta visão ampla significaria, em outras palavras, repensar a historicidade da(s) teoria(s) da arte a começar desta visão que a coloca dentro de uma tradição (e suas consequências para esta tradição) e de sua exegese hermenêuticofenomenológica, i.e.: como ela estabelece um diálogo que nos ajuda a entender o nosso próprio presente:

Compreender um acontecimento passado não é, como pretendeu o historicismo, recuperálo em termos do seu próprio horizonte (pois isso é impossível) mas empreender um diálogo com o passado, ou construir uma mediação histórica - e, portanto, mutável - entre a tradição do intérprete e aquela que busca interpretar (ALVES; RABELO; SOUZA, 2014, p. 194).

Nossa perspectiva se utiliza do método hermenêutico-fenomenológico em sentido amplo, calcado em grande parte no horizonte interpretativo aberto por Martin Heidegger sobre a história do ocidente como metafísica - tema que ele retoma de forma crítica em muitas de suas obras. Desde Ser e Tempo (1976) que ele entende a história da filosofia ocidental como correlata da história da metafísica, esta cuja origem remontaria até Platão, como Lins e Rockmore (2005) enfatizam.

Com a metafísica se consuma uma reflexão sobre a essência do ente e uma decisão sobre a essência da verdade. A metafísica funda uma época, na medida em que the concede o fundamento da sua configuração essencial através de uma interpretação específica do ente e de uma acepção específica da verdade. Este fundamento governa todas as manifestações que caracterizam uma época (HEIDEGGER, 2005, p. 1).

Assim, a relação entre os dois filósofos é crucial para a compreensão da questão - e, talvez, até para toda a plausibilidade das críticas pós-modernas à metafísica, realizadas na esteira do pensamento heideggeriano. Apresentadas as considerações iniciais, podemos, finalmente, colocar a questão do nascimento da teoria da arte no ocidente, também com Platão, em diálogo com a tradição ocidental, de modo a pensar o horizonte hermenêutico desde então aberto e suas consequências.

\section{ARTE, VERDADE, BELEZA}

Uma observação se faz ainda importante: isso que desde a modernidade se entenderá como Belas artes, não existia ainda na Grécia Antiga. A Techne (palavra grega que será traduzida na Idade média latina por Ars, a qual, por sua vez, dará origem posteriormente à palavra arte em língua 


\section{Luciana da Costa Dias}

portuguesa) não era sinônimo apenas das chamadas grandes artes - música, pintura, escultura etc., àquelas nas quais pensamos hoje quando se fala em arte. Antes, era uma palavra de sentido bem mais geral, implicando em um "saber-fazer".

Ou seja, se procurarmos a origem etimológica de "arte" (FERRATER-MORA, 1998), veremos que este termo deriva do latim ars, o qual significa "habilidade em fazer alguma coisa", ou ainda que incorpora toda espécie de atividade humana submetida a regras, vindo a abranger a criação de qualquer tipo de objeto e detendo, em sentido lato, o significado de "habilidade, destreza" e, em sentido estrito, de "instrumento, ofício, ciência". Ars foi a tradução latina da Techne grega, que também se referia a um saber fazer.

Significa isso que a pintura, a poesia, a música, não tem lugar à parte no vasto conjunto da Techne? Certamente que não, mas tampouco são definidas, como as 'belas-artes' modernas, pela expressão da beleza. Inversamente, a beleza quase nunca se encarna, em Platão, nas obras de arte (LACOSTE, 1986, p. 20).

A rigor, não há de fato uma teoria estética em Platão. O que há, são considerações sobre o papel pedagógico da poesia e sobre a beleza - entendida por ele como expressão do ideal suprassensível. Outros diálogos, como o Banquete (PLATO, 1994) tratam da questão do Belo, mas neste texto, como em Platão no geral, esta questão é ontológica e não estética e o belo converge com o bom e o verdadeiro na dialética ascendente. A questão do belo como "produto" da atividade criadora do artista não é sequer posta em questão - pois para Platão, assim como a arte não pode produzir a verdade, também não poderia produzir beleza, que é atributo da ideia.

Existe, pois, em Platão, uma arte do belo, mas essa arte é a dialética, a arte suprema segundo o Filebo, e não uma das belas artes no sentido moderno ('saber produzir belas coisas que dão prazer'). A arte platônica do belo procura purificar o prazer e substituí-lo pela apreensão intelectual das essências. A beleza, por outro lado, embora sensível, não é própria das obras de arte e conduz, de fato, à ascese. A arte da imitação, sob esse ponto de vista, é sobretudo um obstáculo à busca da beleza, dado que convida, primordialmente, a permanecer no mundo sensível que ela reproduz (LACOSTE, 1986, p. 20).

Assim, fica evidente que a compreensão da questão da arte a partir de Platão é dependente da compreensão geral de seu pensamento, e que é preciso esmiuçar este em seus aspectos mais gerais, enfatizando sua visão de mundo em sua afirmação de uma realidade inteligível regida pela harmonia do Cosmos atingível em seu Eidos e em sua realidade racional. Platão afirmava a existência de um mundo racional suprassensível, o mundo ideal, em oposição ao mundo mostrado pelos sentidos, que conduziriam ao erro, ao engano e ao efêmero. 
Ao buscar explicar o que é a realidade, Platão encontra uma explicação através de um estratagema: ele "quebra" o real em dois níveis, o mundo sensível (o nível conhecido pelos sentidos, ilusório e enganoso) e mundo ideal ou inteligível (o nível alcançado apenas racionalmente e, por isso mesmo, a "verdadeira realidade"). E com esta divisão, haveria também uma hierarquização da realidade: o sensível não seria mais do que uma cópia mal feita ou mesmo uma sombra distorcida do inteligível.

E isso se daria de tal forma que, desde então na história da filosofia, o processo do conhecimento sempre requereria um desvencilhar-se de aparências "enganosas e movediças" e a busca da essência imutável e racional por trás do percebido. Assim, aquilo que, pura e simplesmente se mostra aos sentidos, para ele seria sempre alvo de desconfiança. É por isso que, usualmente, se entende o pensamento de Platão como o começo de toda "metafísica", isto é, de toda compreensão da realidade que depende não apenas deste mundo físico, mas de um “outro mundo", não atingível apenas através de nossos sentidos (visão, audição etc.). Com isso a metafísica - marca do pensamento ocidental a partir de então - teria sua origem na própria cisão da realidade. E mais, para Platão, o próprio objetivo de se aprender filosofia seria o de aprender a se distanciar do erro e dos sentidos, indo em direção à verdade ideal, racional, eterna e perfeita.

Como destaca Suassuna em seu tratado de estética, existe uma identificação final entre Verdade, Beleza e o Bem: "A Beleza é o brilho ou o esplendor da Verdade" (Platão apud Suassuna 2005, p. 47) é uma famosa citação platônica e que acentua o caráter de conhecimento do ideal atribuído à fruição da Beleza.

Somente no contexto desta sua visão metafísica de mundo é que sua crítica ao trabalho dos pintores e outros artífices como sendo mímesis - cópias são valorizadas porque produzem imitações das coisas do mundo (mundo sensível), e, por isso, ao invés de conduzir o homem de volta a visão das ideias, à verdade inteligível (mundo ideal), o prenderia na multiplicidade sensível e no erro pode ser entendida.

Platão define essas artes não pela beleza, mas pela mímesis, ou seja, por uma inferioridade ontológica, pelo distanciamento das verdadeiras realidades, das Ideias, às quais a Beleza, por um movimento inverso, deve reconduzir (LACOSTE, 1986, p. 17).

Então, se por um lado aquilo que desde a modernidade se entenderá como arte são as chamadas Belas Artes, as quais giram em torno de conceitos como beleza e harmonia, por outro lado, 


\section{Luciana da Costa Dias}

não é isto que está em jogo em Platão, para quem a compreensão de arte giraria em torno do conceito de mímesis - sendo não mais do que uma "imitação da realidade". Neste sentido, um pintor por exemplo, produz fantasmagorias, porque sua pintura imita o real, por ser uma cópia imperfeita do ideal. A arte não produz beleza para ele, pois a beleza, ao contrário, conduziria necessariamente à verdade, que é de outra ordem (superior) de realidade.

Vemos assim que a concepção de Platão sobre a arte é indissociável de sua concepção ontológica (de "ser" e de "verdade"). Sua crítica à arte (mais propriamente à pintura e à poesia) tem o mesmo cerne de sua crítica à Sofística, se dando pelo grau de afastamento de ambas com relação à verdade, muitas vezes parecendo vagar na simples doxa, não sendo capaz de conduzir o homem à verdade. Ao contrário: a arte criaria eidolon ("ídolos"), falsas imagens distantes das verdadeiras ideias. A pintura cria ilusões do real, algo que mesmo a poesia, se tiver o direcionamento errado pode o fazer, quando por exemplo, criar uma falsa imagem dos deuses - sendo este um dos pontos principais de sua crítica a Homero apresentada na República (PLATÃO, 1993). Para Platão, é necessário que tenhamos sempre a verdade em vista.

Não deixa de ser curioso observar que as primeiras considerações teóricas das quais se tem sobre o que é arte e qual é seu papel, se construam logo pelo viés de uma crítica. Desde então, a arte enfrentará muitos detratores e somente com a modernidade este viés mudará.

Contudo, como explicita Jaeger, em sua obra Paidéia (2002), não se pode jamais esquecer que Platão é "pedagógico": o objetivo subjacente a seus diálogos (e mesmo à cidade idealizada que constrói) é o da educação da alma, a educação do olhar em direção ao eidos, com a exclusão de tudo aquilo que pudesse atrapalhar este processo. Não é correto apenas sustentar uma posição radical de Platão "contra a arte", como muitas vezes foi feito, pois isto jamais esteve em questão para ele. O relevante é entender aí que ele vinculou o problema do Belo necessariamente ao problema da verdade, na medida em que o bom, o belo e o verdadeiro convergem em seu pensamento. $E$ isso sim - a relação arte e verdade - seria uma marca das discussões sobre a arte desde então e pode ser considerado como o início de toda filosofia da arte. Foi a primeira vez que a pergunta pela arte foi posta no ocidente (até onde temos registro) e ao ser colocada, acabou por abrir um horizonte no qual esta, por seu caráter de mímesis, se torna uma forma inadequada de alcançar o conhecimento ideal. É assim, por uma via negativa e não afirmativa que a questão da arte será pela primeira vez posta em questão, discutida e teorizada, o que já de início abre um âmbito hermenêutico específico 


\section{Luciana da Costa Dias}

de interpretação e discussão da questão, o qual será absorvido e sucessivas vezes retomado ao longo de toda a tradição ocidental, como iremos agora esboçar.

\section{A PERSPECTIVA HEIDEGGERIANA SOBRE PLATÃO: A ARTE E A VERDADE NA TRADIÇÃO}

Em suas considerações sobre a história da estética, Heidegger (2007) entenderá que, por Platão ter determinado antes a filosofia como metafísica, o saber que permite o entendimento real das coisas, e não das "sombras na caverna", é que depois ele poderá proceder à seu questionamento sobre a beleza e, por extensão de sentido, sobre a arte. Na República (1993), decide-se a relação metafísica entre arte e verdade e a posição subordinada da arte nos modos de acesso ao conhecimento. $E$, desde então, a pergunta por qual é a verdade da arte e qual seu status será, como observa ainda Heidegger, decisiva para toda a abordagem posterior da arte.

Além disso, como Peter Kraft (1984), em eco a Heidegger enfatiza, estamos - nós, "ocidentais" - mesmo que não o saibamos, presos em um background conceitual metafísico. E com a "teoria da arte" não foi diferente. Assim, não se pode deixar de mencionar a mesma desvalorização progressiva que o "sensível" acabaria por ter - quando da recepção do pensamento platônico no horizonte latino e medieval, - será também de certa forma transferida à arte.

Varrão, escritor romano do século II d.C., fará - com base em Aristóteles - a classificação perdurada por todo o horizonte medieval: "artes liberais" (aquelas dignas do homem livre - como gramática retórica, lógica, aritmética, geometria, astronomia e música) versus "artes servis" (ou "artes mecânicas", as próprias do trabalhador manual e/ou dos servos - atividades "braçais" tais como pintura, escultura, arquitetura, tecelagem, medicina, etc.). Posteriormente, São Tomás de Aquino justificará tal diferença a partir da própria cisão radical cristã entre alma ("racional") \& corpo: "somente a alma é livre, o corpo para ela é uma prisão, de sorte que, da mesma forma as artes liberais são superiores às artes mecânicas" (LACOSTE, 1986, p. 9).

Ocorreu que a cisão inicial da realidade proposta por Platão ("sensível / inteligível") teria se alargado cada vez mais a longo da história do ocidente, até parecer um abismo intransponível, assumindo diferentes faces ao longo do pensamento ocidental (se desdobrando em diferentes dicotomias correlatas como: "corpo / alma", "aparência / essência”, "sujeito / objeto", "razão / sensibilidade", etc.), mas nas quais tudo o que fosse ligado ao corpo e aos sentidos seria sempre inferiorizado. 


\section{Luciana da Costa Dias}

Por extensão, na Idade Média a separação entre sensível e inteligível seria associada ao próprio dogma cristão, por meio da confluência entre filosofia e teologia. O mundo ideal seria equiparado ao plano do divino e o sensível, assimilado ao erro, ao engano e ao pecado - totalmente desprovido de verdade em si mesmo, antes sua veracidade dependeria de sua correspondência com o ideal/divino transcendente. Do mesmo modo em que o ideal será associado ao divino transcendente - ao paraíso e à alma, o corpo, matriz dos sentidos, será associado ao engano e sobretudo ao pecado.

\footnotetext{
A dinâmica da sociedade e da civilização medievais resulta de tensões: entre Deus e o homem, entre o homem e a mulher, entre a cidade e o campo, o alto e o baixo, entre a riqueza e a pobreza, entre a razão e a fé, entre a violência e a paz. Mas uma das principais tensões é aquela entre o corpo e a alma. E, ainda mais, as tensões no interior do próprio corpo. (...) O corpo é o grande perdedor do pecado de Adão e Eva revisitado. (...) Dessas consequências corporais do pecado original a Idade Média tirou conclusões extremas (LE GOFF; TRUONG, 2006, p. 11).
}

No contexto medieval, a verdade é a verdade revelada, sem necessidade de nenhum tipo de concatenação com "as coisas mesmas", com o factual-empírico, para ser alcançada. O corpo, os sentidos, o homem, a arte... Tudo é visto como pecado e engano. E do mesmo modo, vimos acima como a Idade Média também não valorizava a figura do artista "servil" ou de suas criações - de nada que possa induzir ao "prazer sensível", visto como pecado (LAUAND, 1986).

Será somente a partir do Renascimento - e da ênfase cada vez maior na subjetividade trazida pela modernidade - que o papel do artista começa a ser valorizado. A busca da dignidade do homem (a qual o humanismo nascente no Renascimento procurou realizar), foi também a luta pela dignidade da arte - entendida então como a atividade criadora do homem por excelência). Com isso, o artista deixou de ser aquele que "imita" o real, passando a ser aquele que o "aperfeiçoa". E somente a partir daí poder-se-á falar em belas artes - a arte bela como a arte livre, a arte desinteressada (a qual, não podemos deixar de apontar, ser uma conceituação que traz ainda um "ranço" de oposição à antiga classificação como artes servis ou mecânicas), fruto da criação subjetiva do artista, o qual não é mais um ser fadado ao erro, mas pode ser comparado ao próprio demiurgo platônico (PLATÃO, 2001).

Não é nenhuma novidade dizer que de certo modo, o ocidente começou com a Grécia. Afinal, não podemos desconsiderar a influência da matriz grega para o horizonte conceitual no qual nosso mundo ocidental construirá. Como Lins Brandão (2002, p. 31) coloca, os gregos são “o passado 


\section{Luciana da Costa Dias}

histórico e cultural do ocidente", uma de nossas muitas matrizes, a qual somada principalmente à matriz judaico-cristã deu origem àquilo hoje chamado de mundo ocidental.

De fato, o próprio conceito de racionalidade e de subjetividade, marcas da visão de mundo ocidental, começam lá a se fundamentar e depois alimentados pelo Cristianismo durante a Idade Média, se tornam determinantes da Modernidade e do pensamento, valores e cultura ocidentais desde então.

Até hoje, somos herdeiros do pensamento grego: nossas ciências (matemática, arquitetura, medicina etc.), nossas instituições (democracia, república, direito - entre outras) e muitas outras coisas começaram lá a se determinar e até hoje detém uma marca grega, mesmo que muitas vezes não saibamos disto. Tal não podia ser diferente com a "Arte": desde então presa a uma briga dialética com a verdade e a beleza (BADIOU, 2002).

Desde finais do século XVIII, a arte se constituirá como um domínio específico de produção e reflexão, o "domínio estético", consolidado sobretudo com Kant e depois com Hegel e sua defesa da possibilidade de se fazer da estética um campo da filosofia ou uma "ciência da arte". Hegel via a arte e o belo também como conteúdo espiritual - verdade espiritual e não apenas fonte de sensações - o qual deveria ser estudado e mapeado, por já apontar para uma historiografia das formas artísticas. O modo como Heidegger irá conduzir sua discussão acerca do conceito de arte, em A origem da obra de Arte (2000), pretende marcar algo de muito novo: primará por sua tentativa de abordagem direta do fenômeno artístico, pretendendo iniciar a questão "sobre novas bases", para além do modo como a tradição (estético-metafísica) a põe. Neste sentido, até a própria compreensão da história - ou seja, de nossa própria relação com a tradição - precisa ser recolocada (DIAS, 2014).

É importante destacar que a compreensão que Heidegger pretende em sua abordagem do fenômeno da arte requer recolocar criticamente conceitos "tradicionais" da abordagem estética (como o par matéria e forma ou o mesmo o conceito de mimesis) - firmados em uma longa tradição metafísica que encontrariam suas raízes no modo como a filosofia pensara a arte desde a Antiguidade grega.

Isso é possível porque já em seus textos sobre Nietzsche (2007), Heidegger nos fala que existem "palavras fundamentais", cujo sentido muda radicalmente ao longo do tempo uma vez que depende do próprio âmbito histórico e hermenêutico no qual se inserem, i.e.: dependem de seus contextos históricos para serem entendidas. Os textos de Heidegger sobre Nietzsche são curiosos. 


\section{Luciana da Costa Dias}

Foram publicados como uma obra dividida em dois volumes - Nietzsche I e Nietzsche II - e são derivados de uma série de cursos sobre Nietzsche que Heidegger realizara em Freiburg entre os anos 1936 e 1940. De certa forma, nestas Vorlesungen, Heidegger continuará o trabalho iniciado no ensaio de 1931-32, intitulado A teoria platónica da verdade (2009), no qual já tentara elucidar o significado de Nietzsche para a derrubada da metafísica platônica. Porém, nestas preleções ele foi mais longe em sua compreensão de metafísica e correlação desta com o movimento historial do Ocidente em seu primeiro começo platônico.

Em sua obra Nietzsche I, o autor explica que arte pode ser considerada como uma das "palavras fundamentais" (as outras são verdade, beleza, ser, conhecimento, história, liberdade), aquelas a cujas relações a existência humana está expressamente referida. Portanto, para estas se faz necessário uma clarificação, devido ao caráter velado da essência do que é denominado em tais palavras em cada época.

As palavras fundamentais são históricas. (...) Elas são agora e continuarão sendo futuramente fundadoras de história, sempre a cada vez segundo a interpretação que predomina [em sua época]. A historicidade assim compreendida das palavras fundamentais é uma das coisas que precisam ser necessariamente atentadas em meio ao pensamento interessado em pensar através de tais palavras (HEIDEGGER, 2007, p. 131).

Como Heidegger nos mostra, a oscilação de tais palavras seria a própria respiração da história, não é apenas o conteúdo formal da significação da palavra que é diverso, mas também a pertinência do dizer a um mundo. Refletir sobre como estes conceitos se transformam ao longo do tempo é refletir sobre as mudanças das visões de mundo em seus horizontes hermenêuticos. Neste sentido, com a crescente ênfase na subjetividade, marca da modernidade, o conceito de arte mudará radicalmente (bem como os demais conceitos fundamentais da filosofia). A filosofia moderna abordará a arte como estética, que se desenvolve com a entrada da questão da arte no interior da tradição ocidental, isto é, da metafísica.

Na verdade, para Heidegger, o que é arte, o que ela foi ou o que virá a ser, o acesso filosófico imediato à essência da arte é algo que se mostrará problemático em toda a história da metafísica. Aliás, é latente que Heidegger se distanciou daquilo que a modernidade usualmente entenderia como "estética". Para o autor, a incerteza ou o desconhecimento do que a arte em verdade é, foi algo fortalecido na obra dos modernos, a ponto de podermos dizer que não encontramos em Heidegger nenhuma teoria estética, pelo contrário: na medida em que a importância da arte em sua 


\section{Luciana da Costa Dias}

relação com a historicidade fundamental de cada época se mostra, e na medida em que a crítica à tradição metafísica se consolida (da qual a filosofia estética faria parte), vemos como se Heidegger pretendesse "desestetizar" a arte - e para entendermos o significado disso, é preciso ter uma visão do que a metafísica significa para este autor: a própria tradição ocidental, como discutimos ao longo deste artigo.

O mundo hoje é o mundo das multiplicidades, das muitas formas de beleza, das muitas verdades (ou da pós verdade?), no qual não há mais padrões absolutos, nem para a arte, nem para nada. A arte hoje assiste à explosão do inconsciente e do irracional (como no surrealismo ou dadaísmo) e ainda assim, reflete a natureza humana, sua história e suas transformações. Aliás, poderíamos, como Heidegger, dizer que a criação artística é sempre reflexo do mundo onde surge e que na época contemporânea - momento máximo de questionamento ao modelo de racionalidade grega que perseverou no ocidente até então - esta segue pelo mesmo caminho de questionamento e de busca por caminhos ainda por trilhar.

\section{CONSIDERAÇÕES FINAIS}

Neste artigo, não pretendemos responder o que é arte. Não há como responder senão de maneira múltipla: mais de dois mil anos nos separam de Platão e seus primeiros questionamentos. Inúmeros filósofos depois dele e a partir do horizonte aberto, recolocarão a questão. Pretendemos destacar que esta pergunta - assim como todas as perguntas realmente importantes - contempla não apenas uma, mas muitas respostas que dependem essencialmente dos contextos hermenêuticos nos quais são postas e interpretadas. Em dois mil anos de pensamento ocidental, muitas foram as respostas dadas a esta pergunta. Contudo, uma origem em comum pode ser mapeada: o solo no qual a pergunta foi colocada pela primeira vez. Na Grécia de Platão, a Arte deveria ser posta a serviço do Estado e tinha o dever de ensinar o homem. Nos dias de hoje, não se pode mais ter esta pretensão, sem que se pense nos regimes totalitários que moldaram o século XX. Ao contrário, a arte hoje trará a marca do contemporâneo e não se preocupará mais em expressar ou não a verdade ou imitar o real, pelo contrário.

A superação da relação entre arte e verdade só pode se dar dentro de um abordagem hermenêutico-fenomenológica ampla a qual recoloca a arte para além da estética, fortalecida ao longo do século XX e presente no trabalho de diversos artistas e performers. Assim, velhas dicotomias 


\section{Luciana da Costa Dias}

modernas - entre pensamento e corpo, linguagem e ação, palavra e gesto, arte e realidade - perdem sentido. Com isso, o próprio campo epistemológico das Artes precisa ser radicalmente questionado e as (pré-) concepções de origem metafísica, superadas. John Sallis (1995, p. 77), em artigo intitulado Mimesis and the End of Art é categórico ao concluir que é preciso superar "o velho medo socrático do insidioso poder de engodo e corrupção das fantasmagorias produzidas pela arte".

A estrada adiante permanece longa. Portanto, como tarefa futura permanece delimitar o arcabouço teórico que concerne a esta mudança de perspectiva sobre o corpo (e a arte) na tradição filosófica, também localizando-a dentro da grande mudança ocorrida na teoria da arte no século XX: o fim da concepção (moderna) de arte calcada nas obras de arte e na evolução histórica e linear dos estilos artísticos. Essa perspectiva se esgotou em direção a novas formas de fazer e experienciar arte, como buscamos apresentar. Arthur Danto, em sua conhecida obra Após o fim da arte (2006), coloca que hoje a pergunta 'o que é arte? / isso é arte?' perdeu sentido e que deveríamos perguntar: 'quando é arte?', ou em outras palavras: 'em que condições a arte acontece’?

\section{REFERÊNCIAS}

ALVES, Paulo César; RABELO, Míriam Cristina; SOUZA, lara Maria. Hermenêutica-fenomenológica e compreensão nas ciências sociais. Sociedade e Estado. Brasília, v. 29, n. 1, p. 181-198, abr. 2014. Disponível em: http://www.scielo.br/scielo.php?script=sci_arttext\&pid=S010269922014000100010. Acesso em: 14 nov. 2019.

BADIOU, Alain. Arte e Filosofia. In: BADIOU, Alain. Pequeno manual de inestética. São Paulo: Estação Liberdade, 2002. cap. 1, p. 11-28.

DANTO, Arthur Coleman. Após o fim da Arte: a Arte Contemporânea e os limites da História. São Paulo: Odysseus, 2006.

DIAS, Luciana da Costa. Arte e história do ser: algumas considerações sobre o caminho do pensamento de Heidegger a partir do ensaio A origem da obra de arte. Ekstasis: Revista de Hermenêutica e Fenomenologia, v. 3, n. 1, p. 67-77, 2014. Disponível em: https://www.epublicacoes.uerj.br/index.php/Ekstasis/article/view/12792. Acesso em: 14 nov. 2019.

FERRATER-MORA, José. Dicionário de Filosofia. São Paulo: Loyola, 1998.

GADAMER, Hans-Georg. Verdade e método I. Petrópolis: Vozes, 2004.

HEIDEGGER, Martin. A teoría platónica da verdade. In: HEIDEGGER, Martin. Marcas do caminho. Petrópolis: Vozes, 2009. p. 215-250. 


\section{Luciana da Costa Dias}

HEIDEGGER, Martin. A época das imagens de mundo. Tradução de Claudia Drucker. [S.l., s.n]: 2005. Disponível em: http://ghiraldelli.pro.br/wp-content/uploads/Heidegger-A-\%C3\%89poca-dasImagens-de-Mundo.pdf. Acesso em: 19 nov. 2019.

HEIDEGGER, Martin. A origem da obra de arte. Lisboa: Edições 70, 2000.

HEIDEGGER, Martin. Sein und Zeit. Tübingen: Max Niemeyer Verlang, 1976.

HEIDEGGER, Martin. Nietzsche. Rio de Janeiro: Forense Universitária, 2007. v. 1-2.

JAEGER, Werner. Paidéia: a formação do homem grego. São Paulo: Martins Fontes, 2002.

KOSELLECK, Reinhart. Espaço e experiência e horizonte expectativa: duas categorias histórica. In: KOSELLECK, Reinhart. Futuro passado: contribuição à semântica dos tempos históricos. Rio de Janeiro: Contraponto, 2006. p. 305-327.

KRAFT, Peter. Das anfängliche wesen der kunst: zur bedeutung von kunstwerk, dichtung und sprache im denken Martin Heideggers. Frankfurt: [s.n.], 1984.

LACOSTE, Jean. A filosofia da Arte. Rio de Janeiro: Jorge Zahar, 1986.

LE GOFF, Jacques; TRUONG, Nicolas. Uma história do corpo na Idade Média. Rio de Janeiro: Editora Civilização Brasileira, 2006.

BRANDÃO, Jacyntho Lins. Nós e os gregos. In: MARQUES, Haroldo (org.). Os gregos. Belo Horizonte: PUC-Minas, 2002.

PARTENIE, Catalin; ROCKMORE, Tom. Heidegger and Plato: toward dialogue. Chicago: Northwestern University Press, 2005.

PLATÃO. A República. Lisboa: Calouste Gulbenkian, 1993.

PLATÃO. Timeu. Belém: EDUFPA, 2001.

PLATO. Symposium. Oxford University Press, 1994.

SALLIS, John. Mimesis and the end of art. In: RAJAN, Tilottama; CLARK, David (ed.). Intersections: nineteenth-century philosophy and contemporary theory. Albany: State University of New York Press, 1995. p. 147-169.

SUASSUNA, Ariano. Iniciação à estética. Rio de Janeiro, José Olympio, 2005. 